Article

\title{
Analyzing the Role of Gut Microbiota on the Onset of Autoimmune Diseases Using $\mathrm{TNF}^{\Delta \mathrm{ARE}}$ Murine Model
}

\author{
Vivienne Edwards ${ }^{1,+}{ }^{\dagger}$ Dylan L. Smith ${ }^{1,+} \oplus$, Francoise Meylan ${ }^{2}$, Linda Tiffany ${ }^{1}$, Sarah Poncet ${ }^{1}$, Wells W. Wu ${ }^{3}$, \\ Je-Nie Phue ${ }^{3}$, Luis Santana-Quintero ${ }^{4,5}$, Kathleen A. Clouse ${ }^{1,+}$ and Odile Gabay ${ }^{1, *,+}$ (D)
}

1 Division of Biotechnology Review and Research I, Center for Drug Evaluation and Research, U.S. Food and Drug Administration, Office of Biotechnology Products, Office of Pharmaceutical Quality, Silver Spring, MD 20993, USA; ve59@drexel.edu (V.E.); dsmit267@alumni.jh.edu (D.L.S.); Linda.Tiffany@fda.hhs.gov (L.T.); sarah.poncet@fda.hhs.gov (S.P.); kathleen.clouse@fda.hhs.gov (K.A.C.)

2 Translational Immunology Section, NIH, National Institute of Arthritis and Musculoskeletal and Skin Diseases, Bethesda, MD 20892, USA; meylanf@mail.nih.gov

3 Facility for Biotechnology Resources, Center for Biologicals Evaluation and Research, U.S. Food and Drug Administration, Silver Spring, MD 20993, USA; wells.wu@fda.hhs.gov (W.W.W.); jenie.phue@fda.hhs.gov (J.-N.P.)

4 U.S. Food and Drug Administration, Center for Biologics Evaluation \& Research, Office of Biostatistics and Epidemiology, HIVE, Silver Spring, MD 20993, USA; Luis.santana-quintero@fda.hhs.gov

5 U.S. Food and Drug Administration, Center for Drug Evaluation and Research, Office of New Drugs, Office of Hematology and Oncology Products, Silver Spring, MD 20993, USA

* Correspondence: odile.engel@fda.hhs.gov; Tel.: +1-240-402-0223

+ All authors contributed equally.

check for updates

Citation: Edwards, V.; Smith, D.L.; Meylan, F.; Tiffany, L.; Poncet, S.; Wu, W.W.; Phue, J.-N.; Santana-Quintero, L.; Clouse, K.A.; Gabay, O. Analyzing the Role of Gut Microbiota on the Onset of Autoimmune Diseases Using TNF ${ }^{\triangle A R E}$ Murine Model. Microorganisms 2022, 10, 73. https://doi.org/10.3390/ microorganisms10010073

Academic Editor: Elisabetta Caselli

Received: 27 October 2021

Accepted: 21 December 2021

Published: 30 December 2021

Publisher's Note: MDPI stays neutral with regard to jurisdictional claims in published maps and institutional affiliations.

Copyright: (c) 2021 by the authors Licensee MDPI, Basel, Switzerland. This article is an open access article distributed under the terms and conditions of the Creative Commons Attribution (CC BY) license (https:// creativecommons.org/licenses/by/ $4.0 /)$.

\begin{abstract}
Very little is known about disease transmission via the gut microbiome. We hypothesized that certain inflammatory features could be transmitted via the gut microbiome and tested this hypothesis using an animal model of inflammatory diseases. Twelve-week-old healthy C57 Bl/6 and Germ-Free (GF) female and male mice were fecal matter transplanted (FMT) under anaerobic conditions with $\mathrm{TNF}^{\mathrm{ARE}-/+}$ donors exhibiting spontaneous Rheumatoid Arthritis (RA) and Inflammatory Bowel Disease (IBD) or with conventional healthy mice control donors. The gut microbiome analysis was performed using $16 \mathrm{~S}$ rRNA sequencing amplification and bioinformatics analysis with the HIVE bioinformatics platform. Histology, immunohistochemistry, ELISA Multiplex analysis, and flow cytometry were conducted to confirm the inflammatory transmission status. We observed RA and IBD features transmitted in the GF mice cohort, with gut tissue disruption, cartilage alteration, elevated inflammatory mediators in the tissues, activation of CD4/CD8+ T cells, and colonization and transmission of the gut microbiome similar to the donors' profile. We did not observe a change or transmission when conventional healthy mice were FMT with $\mathrm{TNF}^{\Delta \mathrm{ARE}-/+}$ donors, suggesting that a healthy microbiome might withstand an unhealthy transplant. These findings show the potential involvement of the gut microbiome in inflammatory diseases. We identified a cluster of bacteria playing a role in this mechanism.
\end{abstract}

Keywords: gut microbiome; dysbiosis; Fecal Matter Transplants/Fecal Matter Transplanted (FMT); auto-immune diseases

\section{Introduction}

As research on the immune system has expanded over the last decade, the gut microbiome has been increasingly identified as a key player. The mechanisms involved in its homeostasis or imbalance and its impact on diseases, treatments, and interactions with the mucosal immune system are described today more and more [1-3]. A bacterial or viral origin of chronic inflammatory and auto-immune diseases has been suspected for decades, but it is still unclear whether one specific bacteria or virus could trigger disease etiology. However, a consensus of bacteria and viruses interacting together is becoming a more 
plausible idea. Although we are still in the observational portion of this discovery, more research is emerging that reveals the specific mechanisms underlying the link between bacteria, their metabolites, and the immune system $[2,3]$ The gut microbiome, comprised of $95 \%$ bacteria, fungi, viruses and other microorganisms, is in physiological homeostasis in healthy humans $[4,5]$. An imbalance, called dysbiosis, results in pathophysiological mechanisms and events leading to metabolic changes and the initiation of disease states [6]. Interesting correlations, such as the brain-gut axis and joint-gut axis, have been uncovered, shedding light on our understanding of how the human body's systems function and interact as a whole $[7,8]$. The expansion and exponential increase in auto-immune diseases over the last few decades are inversely correlated to the decrease of infectious diseases, due to increased hygiene, better health care and vaccinations [9]. Among autoimmune and inflammatory diseases, rheumatologic diseases such as rheumatoid arthritis (RA), lupus, spondyloarthritis and psoriatic arthritis are prevalent. Inflammatory Bowel Diseases (IBD), such as Crohn's disease and ulcerative colitis, are also predominant and growing in the population. In this context, some discoveries have been made in the joint-gut axis, leading to new therapeutic targets and potential novel drug development in the future. Jose Scher et al. intensively worked on RA and the gut microbiome and have shown involvement of the bacteria Prevotella copri in the etiology of RA [10]. The potential for treatment by fecal transplant has also been investigated and preliminary data in the braingut axis have shown some promising results in Alzheimer and Parkinson diseases [11-13], as well as in IBD, by autologous fecal microbiota transplantation [14]. Although FMT has been utilized in research as a potential therapeutic, it has not been looked at in many studies as a tool of disease transmission; FMT has been investigated in obesity and Parkinson's disease $[15,16]$. One group has shown that transplanting the fecal microbiota of each member of a discordant twin pair-one obese and the second lean-into separate groups of GF mice permits the donors' communities to be replicated, variant features to be identified, and transmission of the phenotype to be performed. The differences were correlated with changes in the fermentation of short chain fatty acids, metabolism of amino-acids, and microbial transformation of bile acid species [17]. We hypothesized that transplanting fecal matter from sick mice into germ free (GF), as well as conventional, healthy (C) mice as their control, could partially transmit some inflammatory disease features. We propose that an already present, healthy microbiome in C mice could conceivably prevent this phenomenon.

As an animal model, we chose the TNF $\mathrm{TARE}^{\mathrm{A} \text { / - }}$ mouse model, largely used to study inflammatory diseases [18-22]. TNF ${ }^{\triangle \mathrm{ARE}}$ transgenic mice overexpress TNF and develop inflammation in tissues and organs, and spontaneously exhibit rheumatoid arthritis (RA) and inflammatory bowel disease (IBD) [23]. TNF ${ }^{\Delta \mathrm{ARE}-/-}$ mice develop severe systemic inflammation and physical disability as they age and do not survive beyond 1 to 2 months of age. However, the heterozygous mice TNF ${ }^{\triangle \mathrm{ARE}} / \mathrm{Het}$, or $\mathrm{TNF}^{\triangle \mathrm{ARE}+\text { /- }}$, develop a similar phenotype and are also disabled as they age but live a longer life, which is why we chose to use this model.

\section{Materials and Methods}

Animals: 12 -week-old GF and conventional SPF C57 Bl-6 mouse groups ( $n=16$ females and $n=20$ males) were provided by Taconic (Taconic Bioscience, Inc., Rensselaer, NY, USA). $\mathrm{TNF}^{\triangle \mathrm{ARE}}$ mice were provided by Prof. Fabio Cominelli, Case Western Reserve University, Cleveland, $\mathrm{OH}$, and housed in the NIH Bdg 10 animal facility. TNF mRNA contains a repeated oligonucleotide AU-rich motif in its $3^{\prime}$ untranslated region, implicated in posttranscriptional and translational regulation of TNF synthesis. Mice bearing an endogenous deletion of the $3^{\prime}$-AU-rich region in the gene encoding TNF possess high circulating levels of TNF protein [24,25]. Fecal Matter Transplantation, FMT was performed within the FDA animal facility. One mouse of each gender underwent FMT with one mouse donor from the same gender. GF mice were housed in a sterile semirigid isolator (SRI) in a dedicated GF room (Park Bioservices, LLC, Groveland, MA, USA) as described in Gabay et al. [1,26]. 
After FMT, GF mice were kept in a gnotobiotic environment in a new isolator for 12 weeks, and co-housed to minimize unwanted variations in the gut microbiome. Fecal samples were collected every other week for monitoring the colonization and the stabilization of the new microbiome. Conventional mice were housed under standard conditions. All mice were co-housed and fed the same diet of autoclaved food and water, housed in autoclaved bedding and kept under standard temperature and light. All animal procedures and the Animal Study Proposal (ASP) were reviewed and approved by the U.S. Food and Drug Administration (FDA) Institutional Animal Care and Use Committee (IACUC).

FMT Preparation and Processing: Three fecal pellets from $\mathrm{TNF}^{\mathrm{ARE}+/-}$ mice or conventional $\mathrm{Bl} / 6$ healthy mice were snap frozen in $150 \mu \mathrm{L}$ PBS and stored at $-80^{\circ} \mathrm{C}$. To preserve as much anaerobic bacteria as possible, all preparations were conducted inside an anaerobic chamber (Type B Coy vinyl anaerobic chamber, Coylab.com, Grass Lake, MI, USA) under sterile conditions. An additional $150 \mu \mathrm{L}$ of anaerobic sterile PBS was added to each tube in the anaerobic chamber, before samples were homogenized with a sterilized Biomasher II (DiagnoCine, Hackensack, NJ, USA) and centrifuged. Then, $150 \mu \mathrm{L}$ of supernatant was aspirated into a sterile single wrapped $1 \mathrm{~mL}$ Monoject Tuberculin Syringe (Covidien, Jersey City, NJ, USA) with a sterile animal feeding needle (Cadence Science, Cranston, RI, USA). Syringes were immediately used for oral gavage. For use in the GF isolator, standard SOP and procedures were used as per protocol described in Gabay et al. [26].

Mice Dissection: Mice were euthanized using $\mathrm{CO}_{2}$ and processed as described in Gabay et al. [1] Briefly, using surgical scissors, a midline cut was made in the abdomen exposing the gut. The small intestine was removed, and four $1 \mathrm{~cm}$ pieces of the gut were cut at the same median between the stomach and the cecum. One piece was placed in $4 \%$ paraformaldehyde, while the remaining three were snap frozen for protein analysis. The remaining gut was processed to isolate lamina propria lymphocytes for further flow cytometry and Lamina Propria immune cell analysis. A colon fecal sample was removed and snap frozen for DNA analysis. A knee and hip were dissected from each mouse and placed in $4 \%$ paraformaldehyde for histological staining and immunohistochemistry (American Histolabs, Gaithersburg, MD, USA; HistoServ, Gaitherburg, MD, USA). Spleens were collected and processed to isolate cells for analysis by flow cytometry.

Genomic DNA Extraction from Fecal Samples: Genomic DNA was extracted using the Power Fecal DNA isolation kit (Mo-Bio, Carlsbad, CA, USA) following the manufacturer's instructions. Each fecal pellet was cut to weigh $0.025 \mathrm{~g}$. Volumes of the solution used to dissolve the pellets were adjusted to this weight. Final elution was done in $80 \mu \mathrm{L}$ of the kit elution buffer.

16S rRNA Library Preparation and Sequencing: 16S rRNA library preparation and sequencing were conducted following the Illumina's 16S Metagenomic Sequencing Library Preparation Guide Rev. B (Illumina Inc., San Diego, CA, USA), reported in our previous study [1]. Briefly, microbial genomic DNA samples were normalized to an equal concentration and $2.5 \mu \mathrm{L}$ of microbial genomic DNA samples were used to create a single amplicon using custom primer pairs specifically targeting variable V3 and V4 regions of the 16S rRNA gene. During the amplification, Illumina sequencing adapters and dual-index barcodes were added to the amplicons. The PCR products were cleaned up and dual indices were attached using Illumina Nextera XT Index kit (Illumina Inc., San Diego, CA, USA) and Kapa HiFi HotStart ready Mix. The final libraries were cleaned up again, quantified and normalized using Bioanalyzer DNA 1000 chip (Agilent Technologies Inc., Santa Clara, CA, USA) and Qubit DNA assay (Life Technologies Corp., Eugene, OR, USA). Libraries were pooled, denatured, and loaded on the Illumina MiSeq and sequenced paired end $(2 \times 300$ cycles) using a MiSeq Reagent Kit v3 (600 cycles). The MiSeq sequencing FASTQ files were generated using MiSeq Reporter software

Bioinformatics analysis of sequencing data using the High-Performance Integrated Virtual Environment (HIVE) platform [27]. The CBER HIVE platform was used to transfer data and perform the bioinformatics analysis, quality control on the sequencing data, as pre- 
viously described in Gabay et al. [1]. The FASTQ files were uploaded into the cloud-based system. Upon data upload, HIVE automatically calculates basic quality control (QC) metrics of sequencing runs, using them to determine if an individual sequence run worked well, as previously described in Gabay et al. [1]. Optimized metagenomic pipeline is then executed using the CensuScope pipeline [28]. The Silva Bacteria database (release 102) with 14,956 sequences [29] is used as a reference to align the short reads and identify reads to specific genomes using the NCBI taxonomy database [30] to find the taxonomic identifier. CensuScope has been parallelized in HIVE. The HIVE CensuScope tool determines the taxonomic composition of a metagenomic sample and provides users with standard formatted reports of hits classified into species or higher taxonomic nodes. Mapping the sequence data to the Silva Bacteria database is done using the basic local alignment search tool (BLAST) [31] with the following parameters: (-task megablast -evalue $1 \times 10^{-6}$-best_hit_score_edge 0.1 -best_hit_overhang 0.1 -num_alignments 1 -num_descriptions 1 ). Our analysis using CensuScope with the suggested parameters (1000 randomly picked reads and 50 iterations) yield a statistical power of $>99 \%$ for detecting taxa, with an estimated error of $3.4 \%$ according to the publication cited.

Regularized Fisher's linear discriminant analysis (RLDA) was performed to detect bacterial populations to identify main discrimination markers among the groups. In Figures 5 and 6, a 3-D plot depicts the results from RLDA, delineating the murine gut microbial profile through vectorization in three-dimensional space. Each marker is representative of one murine sample, with different groups being assigned unique colors. To obtain the 3-D plot, a JavaScript library (Three.js) was implemented to generate interactive graphs that can be manipulated to preview data from various angles, change colors and zoom in/out for a detailed view, also allowing us to save the 3-D plot in PNG format. Our raw data are to be transferred to the NCBI microbiome database registry depository, in the Sequences Read Archives (SRA): https:/ / www.ncbi.nlm.nih.gov/sra/ (accessed on 15 December 2021).

Luminex Analysis: Analysis was conducted using mouse serum and gut tissue samples. Gut proteins were extracted using Tissue Protein Extraction Reagent (ThermoFisher, Rockford, IL, USA) with HALT Protease Inhibitor Cocktail (ThermoFisher, Rockford, IL, USA) in PowerBead Tubes, Metal $2.38 \mathrm{~mm}$ (Qiagen, Hilden, Germany). Tissue was disturbed in the incubating/cooling shaker (VWR, Radnor, PA, USA) at $6000 \mathrm{rpm}$ and supernatant stored in new Eppendorf tubes. Serum and gut protein samples were then prepared using the Bio-Plex Pro Reagent Kit V (Bio-Rad, Hercules, CA, USA), Pro-Mouse Cytokine TNF- $\alpha$ Set, IL-1 $\beta$ Set, IL-6 Set, and IL-17A Set (BioRad, Hercules, CA, USA) with Pro-Mouse Cytokine Standards Group I (BioRad, Hercules, CA, USA). Multiplex experiments were conducted as per manufacturer instructions on the BioRad BioPlex 200 Luminex (Austin, TX, USA).

Histology and Immunohistochemistry: Knees and hips were dissected and fixed in $4 \%$ paraformaldehyde (PFA) for $36 \mathrm{~h}$, then conserved in $70 \%$ ethanol. Joints were decalcified in a solution containing formic acid and paraformaldehyde, after which joints were dehydrated and embedded in paraffin. Gut was dissected, fixed, and conserved using the same method. Sections of $5 \mu \mathrm{m}$ were cut and stained with Safranin'O/light green for the joints and Periodic Acid Shiff (PAS) for the gut. Unstained slides were used to perform Immuno-histochemistry with Rabbit Polyclonal Anti-TNF-alpha Antibody, Rabbit Polyclonal Anti-IL-1 beta/IL-1F2 Antibody, and Mouse Monoclonal Anti-IL-6 Antibody (Novus Biologicals, Littleton, CO, USA).

Flow Cytometry: After euthanasia, spleens were removed and then smashed with a $3 \mathrm{~mL}$ Luer-Lok tip syringe (BD, Franklin Lakes, NJ, USA) through a $40 \mu \mathrm{m}$ Nylon cell strainer (Falcon, Corning, NY, USA) in a $50 \mathrm{~mL}$ tube containing RPMI-1640 complete media (BioWhittaker Lonza, Walkersville, MD, USA) enriched with sodium pyruvate (Gibco, Grand Island, NY, USA) and Penicillin Streptomycin (Gibco, Grand Island, NY, USA). Cells were extracted using 1.2 mL ACK Lysis Buffer (Gibco, Grand Island, NY, USA) for one minute for the removal of red blood cells and resuspended in complete medium. Cells 
were then stained for flow cytometry using FOXP3/Transcription Factor Staining Buffer Set (Invitrogen, eBioscience, Eugene, OR, USA), with LIVE/DEAD ${ }^{\mathrm{TM}}$ Fixable Aqua Dead Cell Stain Kit (Invitrogen, Eugene, OR, USA), lymphocytes using anti-CD3e Percy5.5 (BD Biosciences; Franklin Lakes, NJ, USA) and CD4 and CD8 T-cells using anti-CD4 V450 (BD Biosciences; Franklin Lakes, NJ, USA) and anti-CD8 FITC (BD Biosciences; Franklin Lakes, NJ, USA). Stained cells were immediately run on Fortessa X20 (BD Bioscience; Franklin Lakes, NJ, USA) and analyzed using FlowJo V10.

Statistical analysis: Results were analyzed using ANOVA in JMP 16 and unpaired twosample-t-test analysis GraphPrism software. The green diamonds created by the software JMP16 represent the mean for each group (medium line) as well as the interval estimates for each group (top and bottom points). The groups are represented in the $X$ axis and the percentage of different phyla present in the gut are shown in the $\mathrm{Y}$ axis. Data are presented as mean \pm SEM. A value of $p<0.05$ was considered statistically significant.

Study design: we provide a summary of our study design in Supplemental Figure S1.

\section{Results}

\subsection{Behavioral and Physical Changes}

After fecal microbiome transplants (FMT) in the germ-free colony, GF mice were kept co-housed in a gnotobiotic environment in a new isolator for 12 weeks. Colonization of the gut was monitored every other week by collecting fecal samples. We started to notice behavioral changes at week 8 in the mice fecal matter transplanted (FMT) with $\mathrm{TNF}^{\triangle \mathrm{ARE}+\text { / }^{-}}$ mice as compared to their counterpart controls, GF fecal matter transplanted (FMT) with C, with mice becoming increasingly aggressive over time, exhibiting defensive postures and an increase in biting behavior. In addition to the behavioral changes in GF mice FMT with $\mathrm{TNF}^{\triangle \mathrm{ARE}+/-}$ mice, we found physical changes consistent with IBD and RA: scruffy hair and protective position suggesting pain in the belly, blood in their feces when collecting fecal samples, which became more and more difficult to obtain, as well as deformation in their paw shape (Figure 1, panel (a) and (b)). Comparatively, we did not notice a specific behavioral or physical change in GF mice FMT with $\mathrm{C}$ possessing a conventional, healthy microbiome, which were housed in the same isolator and did not show pictures of those phenotypical control mice. Mice were transplanted with only adult donors, and a potential transmission with early FMT was not tested.

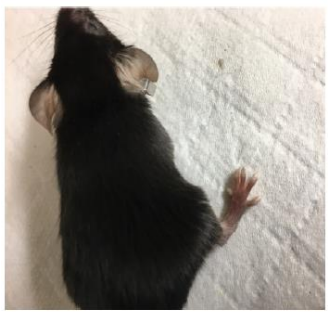

C Donor

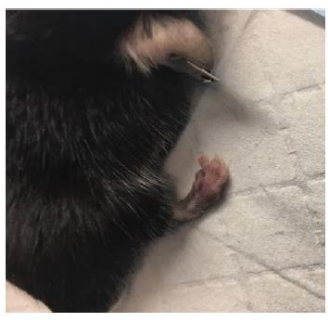

TNF $\triangle A R E$ Donor

(a)

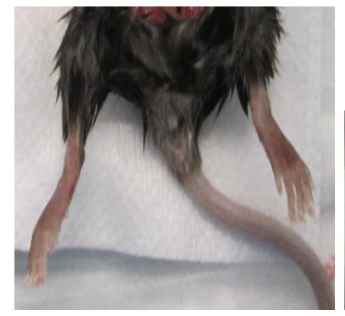

GF FMT C

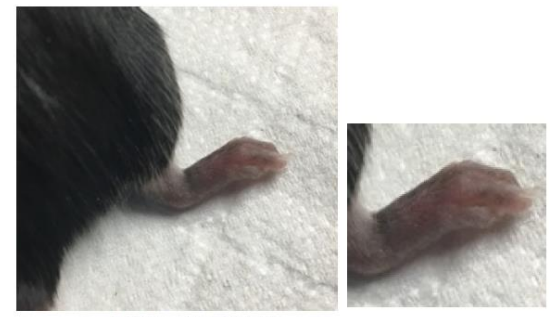

GF FMT TNF $\triangle A R E$

(b)

Figure 1. Macroscopic in vivo phenotypes (a)-Representative pictures of donor mice. Top: male conventional donor control $(\mathrm{C}), n=9$. Bottom: male $\mathrm{TNF}^{\triangle \mathrm{ARE}+/-}$ sick donor with enlargement of the 
right lower limb $(n=11) \cdot \mathrm{TNF}^{\triangle \mathrm{ARE}+/-}$ donor exhibits a degenerative arthritis with deformation and swelling phenotype compared to control. (b) - Picture of GF mice, that received FMT from C

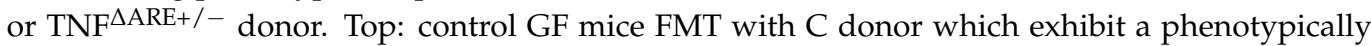
normal paw. Bottom: GF mice FMT with $\mathrm{TNF}^{\triangle \mathrm{ARE}+\text { /- }}$ exhibiting a phenotype with deformation and swelling similar to the $\mathrm{TNF}^{\triangle \mathrm{ARE}+/-}$ donor. Females show the same phenotypic pattern and pictures are representative of the entire colony. Histological examination of the gut and the joints of these

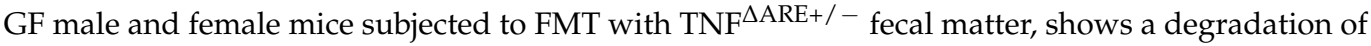
the knee joints (clefts, debris, tears and loss of cartilage) and damages to the gut (thickening of the wall, disorganization of the villi, cell infiltration) compared to the group of male and female GF mice FMT with C mice, panels, see Figure 2a,c. Immunohistochemistry (IHC) was then conducted using anti-TNF antibody. In GF mice FMT with $\mathrm{TNF}^{\triangle \mathrm{ARE}+\text { / - }}$, as compared to GF mice FMT with healthy microbiome, IHC showed significant pro-inflammatory cytokine signature in tissues, particularly in the gut. We can localize the TNF staining in the gut epithelial layer cells and in the chondrocytes of the cartilage surface (Figure 2, panels (b,d) Results were similar between males and females).
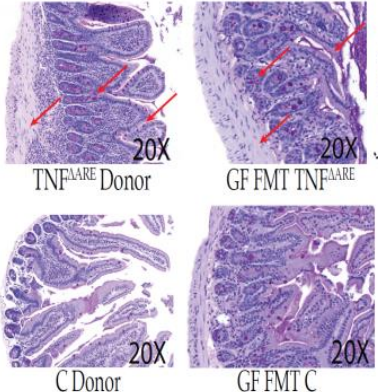

GF FMT TNF ${ }^{\mathrm{AAR}}$

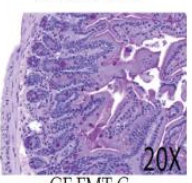

GFFMT

(a)

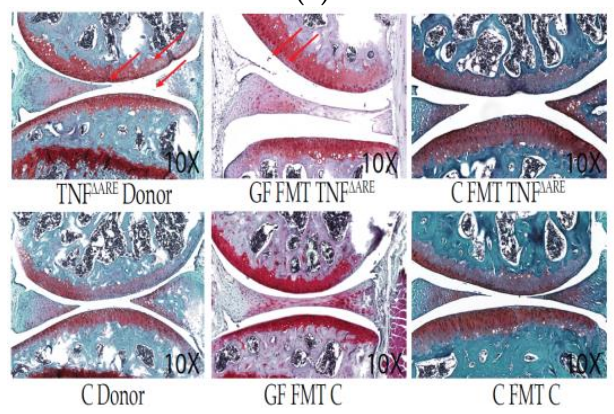

(c)

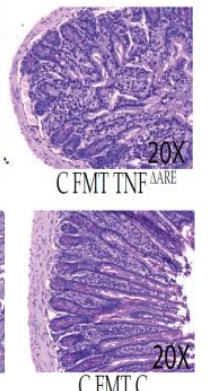

CFMTC

CFMTC

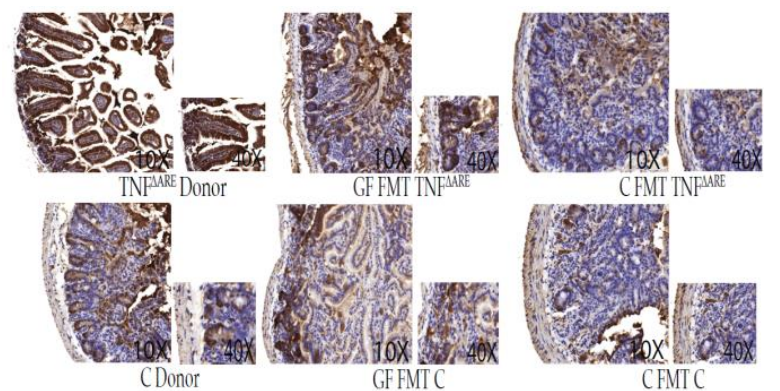

(b)

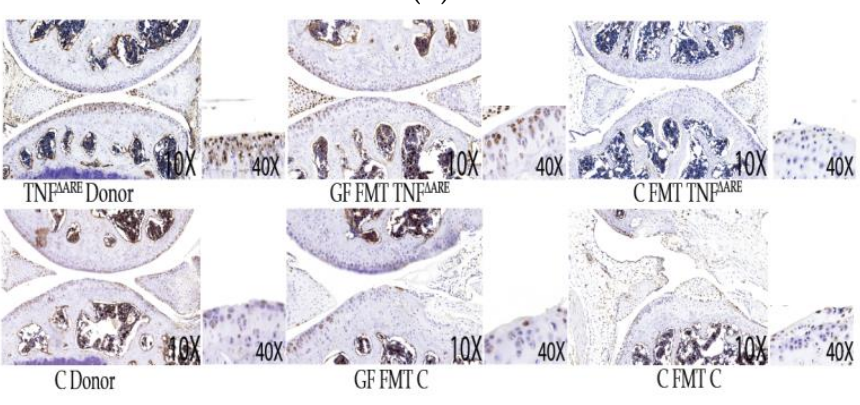

(d)

Figure 2. Descriptive histopathology and immunohistochemistry. Our data shown are representative of $\sim 90 \%$ of similar results in FMT mice Panel (a) - Histological intestinal sections. Representative images were obtained at $10 \times$ magnification as indicated and stained with Periodic Acid Shiff (PAS). Arrows represent thickening of the wall and disorganization, blunting of the villi and cell infiltrations. GF mice FMT with C donor and conventional C mice do not display histological differences or

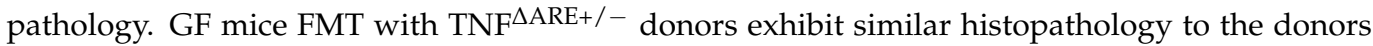
themselves. Panel (b) - Intestinal immunohistochemistry sections. Representative images were obtained at $10 \times$ magnification as indicated. Slides were stained with anti-TNF polyclonal antibody. Massive TNF production is observed in $\mathrm{TNF}^{\triangle \mathrm{ARE}+{ }^{-}-}$donor intestines and GF mice FMT with

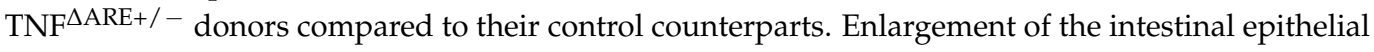
cell layer at $40 \times$ magnification indicates that TNF production is localized in epithelial cells in $\mathrm{TNF}^{\triangle \mathrm{ARE}+/-}$ donors and GF FMT with $\mathrm{TNF}^{\triangle \mathrm{ARE}+/-}$ donors. Other immunohistochemistry cuts display a normal baseline level of TNF, not localized in the epithelial cells. Panel (c): Histological knee sections. Representative images were obtained at $10 \times$ magnification as indicated and stained with

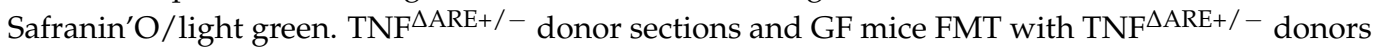
show features of joint degradation indicative of arthritis: Arrows point out clefts, debris, tears and loss of glycosaminoglycans. These features are not observed in controls, C donors, GF FMT with C donors 
and C mice FMT with either donors. Panel (d): Knee immunohistochemistry sections. Slides were stained with anti-TNF polyclonal antibody. Chondrocyte nuclei are stained in blue. Enlargement of the joint surface at $40 \times$ magnification indicates that TNF production is localized in chondrocytes in $\mathrm{TNF}^{\triangle \mathrm{ARE}+\text { / - }}$ donors knee cartilage and in GF mice FMT with $\mathrm{TNF}^{\triangle \mathrm{ARE}+\text { / - }}$. TNF production is not observed in chondrocytes from control mice.

\subsection{Inflammation}

We quantified the pro-inflammatory cytokines TNF and IL-17 and found a level of local basal inflammation in the gut tissue of $C$ mice donors and a higher trend in $\mathrm{TNF}^{\Delta \mathrm{ARE}+/-}$ donors, with a significant elevated level of TNF in the mice FMT with TNF $\triangle \mathrm{ARE}+/$ - compared to their counterparts (Figure 3 panel (b)) Additionally, we found a moderate elevation of the systemic inflammatory marker, IL17A, in the serum of these mice (Figure 3, panel (a).

a.

IL-17A serum levels

after fecal transplant

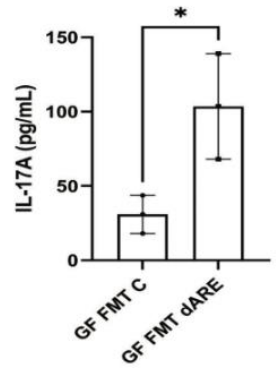

b. TNF Gut Levels

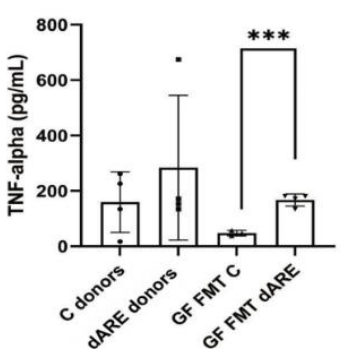

c.

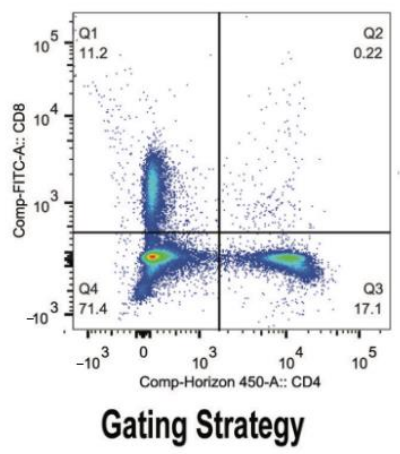

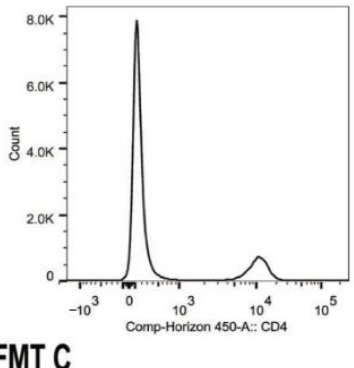

GF FMT C

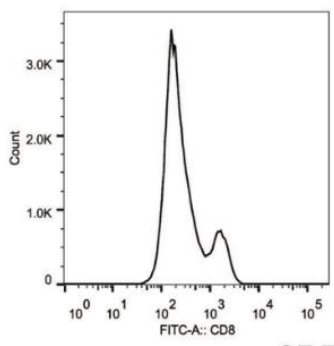

GF FMT TNF $\triangle$ ARE

Figure 3. Proinflammatory cytokines measurement and inflammation evaluation by flow cytometry. GraphPad Prism was used to generate the bar plots, that shows the mean of data and error bars show standard deviation. Stars represent significance $\left({ }^{*}\right.$ for $p<0.05$ and ${ }^{* * *}$ for $\left.p<0.001\right)$. Multiplex ELISA Assay (Luminex). (a) Multiplex assay was conducted on the serum, with antibodies against TNF, IL-1 $\beta$, IL-6 and IL-17. Results show a serological statistically significant $(p=0.0290)$ increase in IL-17A level in serum of GF mice FMT with $\mathrm{TNF}^{\Delta \mathrm{ARE}+/}$ - donors $(n=6)$ compared to their controls, GF mice FMT with C donors $(n=3)$. No significant difference was detected in serum TNF, IL-1 $\beta$ and IL-6 levels. Results were similar between males and females and were representative of the colony. (b) The multiplex assay was conducted at the tissue level after gut protein extraction. TNF

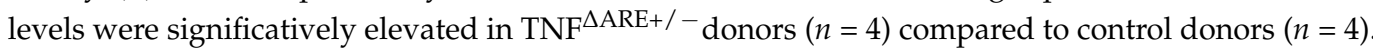
TNF levels were below the limit $\mathrm{f}$ detection in healthy control mice donors. The levels of TNF were significatively elevated in GF mice FMT with $\mathrm{TNF}^{\triangle \mathrm{ARE}+/-}(n=4)$ compared to GF mice FMT with $\mathrm{C}(n=3, p=0.0004)$. (c) -Flow cytometry was conducted on spleen cells using antibodies directed against CD4 and CD8. After gating on lymphocytes, results show an activation and expansion of CD4+ and CD8+ T cells in GF mice FMT with $\mathrm{TNF}^{\Delta \mathrm{ARE}+/}$ - when compared to their counterpart controls, suggesting an immune response initiation and inflammatory status initiation. Data shown from $n=4$ in each group. 
After obtaining immune cells from the spleens, we gated on lymphocytes, then gated on CD4/CD8 positive T-cells and found an activation and expansion of those cells in the GF mice FMT with $\mathrm{TNF}^{\triangle \mathrm{ARE}+/}$ - compared to their counterpart, healthy control mice, from $11.2 \%$ and $17.1 \%$ to $18.8 \%$ and $20.3 \%$, respectively (Figure 3 , panel (c)).

The group of control mice FMT with either control or $\mathrm{TNF}^{\triangle \mathrm{ARE}+/-}$ donors do not exhibit any change in IL-17 levels (under the level of detection) or TNF and there was no peak of $\mathrm{T}$ cells activation shown by flow cytometry.

\subsection{Colonization}

After investigating the gut microbiome taxonomic profile of the TNF $\mathrm{TNR}^{\triangle \mathrm{AR}}$ - and healthy conventional donors, we examined the colonization in two different colonies: GF mice transplanted with $\mathrm{TNF}^{\triangle \mathrm{ARE}+/-}$ donors, compared to GF mice transplanted with healthy controls. After 6 weeks post-FMT, the gut microbial profile of GF mice FMT with either donor stabilized, normalizing to a profile similar to their respective donors' (Figure 4).

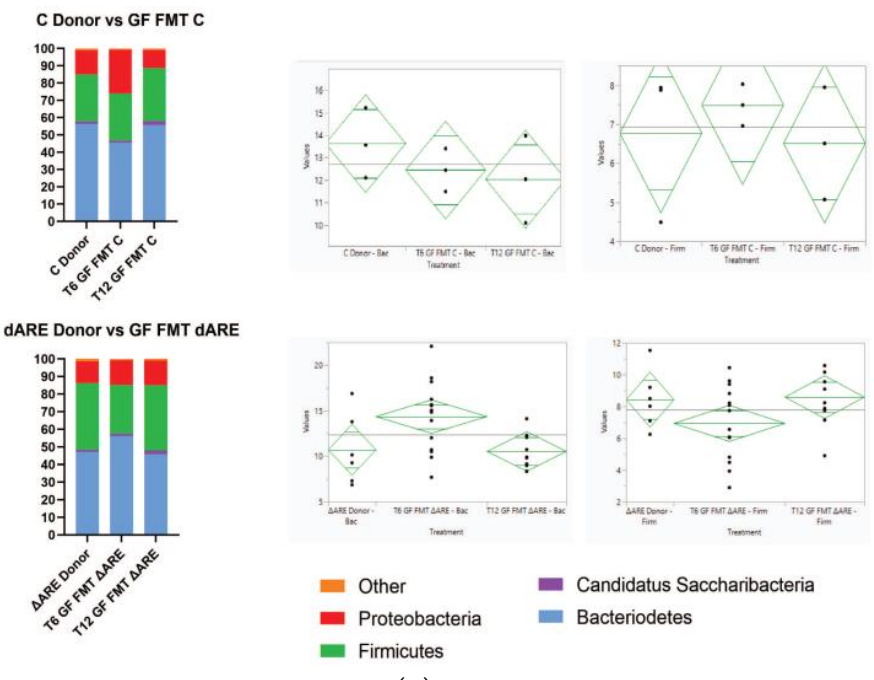

(a)

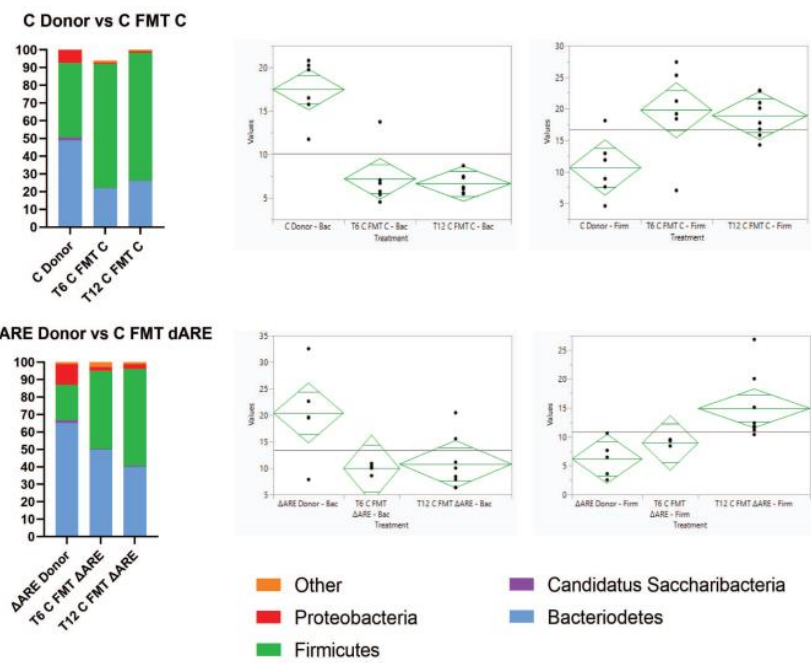

(b)

Figure 4. Colonization overtime of the GF and Control colonies after FMT. Colonization at phyla level. Graph Pad Prism was used for generating the stacked bar graphs and the diamond plots were generated by JMP16 software. They represent the confidence interval of each group. The medium line is the mean of the sample group. The Y axes are the CI range for each group. Panel (a) Phylogenic results after NGS and HIVE bioinformatics analysis showing the gut microbial profile at the phyla level 6 weeks (T6) and 12 weeks (T12) after GF mice were fecal transplanted from C (top) or $\mathrm{TNF}^{\triangle \mathrm{ARE}+/-}$ (bottom). At T6, we observe a reshuffling of the microbiome profile in both GF mice FMT with C donors $(n=3)$ and GF mice FMT with TNF $\triangle \mathrm{ARE}+{ }^{-}$donors $(n=14)$. At T12 weeks, the microbiome profile of recipient mice is completely normalized relative to their donors, both in GF mice FMT with control donors $(n=3)$ and with $\mathrm{TNF}^{\triangle \mathrm{ARE}+/-}$ donors $(n=10)$. ANOVA statistical analysis shows no significant difference between T12 mice and their respective donors $(p>0.05)$, for both the Bacteroidetes and Firmicutes phyla, for GF mice FMT with either C or TNF $\triangle \mathrm{ARE}+$ - $^{-}$. Panel (b) Phylogenic results showing healthy control mice FMT with C (top) or TNF $\triangle \mathrm{ARE}+/-$ (bottom) donors, 6 weeks (T6) and 12 weeks (T12) after fecal transplant. At T6, we observe a reshuffling of the microbiome profile in both C FMT with C donors $(n=6)$ or C FMT with $\mathrm{TNF}^{\Delta \mathrm{ARE}+/-}$ donors $(n=4)$. By T12, the microbiome profile of the recipient mice is significatively different from the donor, for both $\mathrm{C}$ mice FMT with $\mathrm{C}$ donors $(n=8)$ and $\mathrm{C}$ mice FMT with $\mathrm{TNF}^{\Delta \mathrm{ARE}+/-}$ donors $(n=8)$. ANOVA statistical analysis shows a significant difference at T12 between $C$ Donors and $C$ mice FMT with $\mathrm{C}$ donors, for both the Bacteroidetes phyla $(p<0.0001)$ and Firmicutes phyla $(p<0.0001)$. ANOVA statistical analysis shows a significant difference at $\mathrm{T} 12$ between $\mathrm{TNF}^{\Delta \mathrm{ARE}+{ }^{-}-}$donors and $\mathrm{C}$ mice FMT with TNF ${ }^{\triangle \mathrm{ARE}+/-}$ donors, for both the Bacteroidetes phyla $(p=0.0121)$ and Firmicutes phyla $(p=0.0439)$. 
In $C$ mice FMT with either control donor or $\mathrm{TNF}^{\triangle \mathrm{ARE}+\text { / - }}$ donor, we observed no phenotypical behavioral or physical changes in the mice. Histological examination did not reveal any difference in the joints or the gut of $\mathrm{C}$ mice receiving FMT from either donor, when compared to the healthy $\mathrm{C}$ donors (Figure 2, panel (a) and (c)). Immunohistochemistry shows a basic low level of gut inflammation in all mice. There was no increase in inflammatory markers analyzed by multiplex in the gut tissue, with nondetectable levels for all inflammatory markers, and no systemic inflammation observed in both C mice FMT with $\mathrm{C}$ donors, or $\mathrm{TNF}^{\triangle \mathrm{ARE}+/-}$ donors (Figure 2, panel (b) and (d)). The taxonomic analysis shows a similar gut profile of $\mathrm{C}$ mice before and after receiving FMT from healthy or sick donors; there is no observed transmission of the $\mathrm{TNF}^{\triangle \mathrm{ARE}+/-}$ donor microbiome profile in $\mathrm{C}$ mice recipients. Results were similar in males and females. When $\mathrm{C}$ conventional $\mathrm{Bl} / 6$ mice exhibiting a healthy microbiome receive FMT with $\mathrm{TNF}^{\triangle \mathrm{ARE}+/-}$ donors, 12 weeks post-FMT, their overall gut microbial profile remains identical to their pre-FMT profile, regardless if the FMT is done with $\mathrm{TNF}^{\triangle \mathrm{ARE}+\text { / - }}$ donor microbiota or $\mathrm{C}$ healthy control microbiota (Figure 4, panel (a) and (b)).

\subsection{Taxonomy: Phyla Level}

A three-dimensional (3D) representation of the taxonomic data, at both a phyla and genus level, confirms transmission of the $\mathrm{TNF}^{\triangle \mathrm{ARE}+/-}$ donor microbial profile to GF mice but not to $\mathrm{C}$ mice. Clustering is seen between GF mice and their respective donors, but $\mathrm{C}$ mice FMT with either $\mathrm{C}$ or $\mathrm{TNF}^{\triangle \mathrm{ARE}+\text { / - }}$ donors have distinct localization in 3D space (Figure 5, panel (a), Figure 6, panel (a)). A healthy microbiome is characterized by a stable ratio between the two major phyla present in the gut, Bacteroidetes and Firmicutes [32]. A ratio of Bacteroidetes to Firmicutes conveys a big-picture view of the gut health. Although GF mice exhibited ratios similar to their respective donors, C mice FMT exhibited statistically significant different ratios compared to their respective donors (Figure 5, panel (b)).
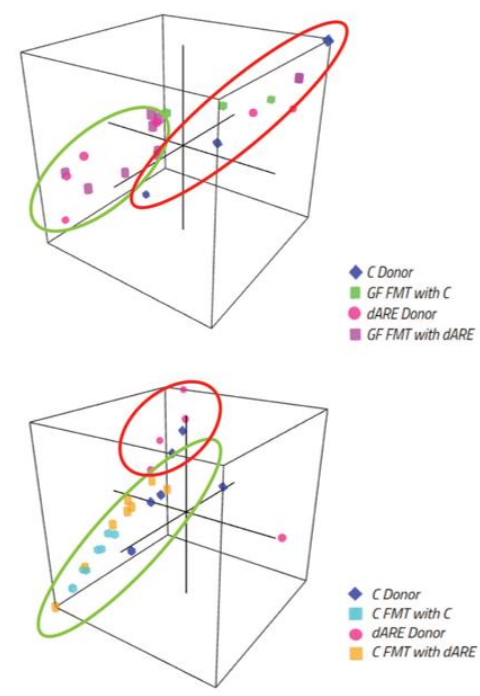

(a)

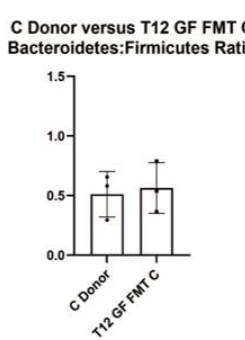
C Donor versus T12 C FMT C
Bacteroidetes:Firmicutes Ratio

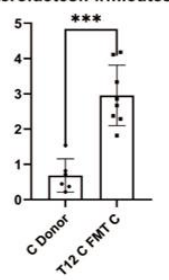

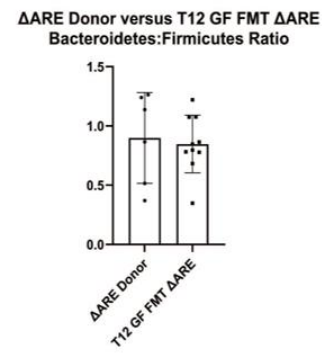

$\triangle A R E$ Donor versus T12 C FMT $\triangle A$ ARE Bacteroidetes:Firmicutes Ratio

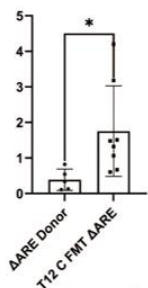

(b)

Figure 5. 3D visualization of phyla communities in FMT colonies and quantification of Bacteroidetes/Firmicutes ratio. GraphPad Prism was used to generate the bar plots that shows the mean of data and error bars show standard deviation. Stars represent significance $\left({ }^{*}\right.$ for $p<0.05,{ }^{* *}$ for $p<0.01$ and $^{* * *}$ for $p<0.001$ ). Taxonomy panel at Phyla level. Panel (a) 3D representation of clustering at the Phyla level. Top: Donors $(n=9)$ and GF mice FMT with Controls or TNF $\triangle \mathrm{ARE}+/-(n=13)$. Clustering indicates that GF recipient mice are localized closely to their respective donor mice together. Bottom: Donors $(n=11)$ and GF mice FMT with Controls or TNF ${ }^{\Delta \mathrm{ARE}+{ }^{-}-}(n=16)-\mathrm{Clustering}$ indicates that $\mathrm{C}$ donors, $\mathrm{C}$ mice FMT with $\mathrm{C}$, and $\mathrm{C}$ mice FMT with $\mathrm{TNF}^{\triangle \mathrm{ARE}+{ }^{-}-}$are localized apart 
from $\mathrm{TNF}^{\triangle \mathrm{ARE}+1-}$ donors. $\mathrm{TNF}^{\triangle \mathrm{ARE}+/-}$ donors are clustered together, but far apart from other groups, indicating a unique 3D localization and microbial profile. Panel (b) Firmicutes/Bacteroides ratio. Top: Comparison between donors and GF mice FMT with their respective donors. No statistical difference is observed in the B/F ratio for C donor $(n=3)$ vs. GF FMT C $(n=3)$ and for $\mathrm{TNF}^{\Delta \mathrm{ARE}+/-}$ donor $(n=6)$ and GF FMT TNF ${ }^{\Delta \mathrm{ARE}+/-}(n=10)$. Bottom: Comparison between donors and Control conventional, healthy mice recipients. Two-way student's $t$-test statistical analysis indicates a significant difference $(p=0.0258)$ in C mice FMT with $C(n=8)$ compared to $C$ donors $(n=6)$, and a significant difference $(p=0.040)$ in C mice FMT with $\operatorname{TNF}^{\Delta \mathrm{ARE}+/-}(n=8)$ compared to $\mathrm{TNF}^{\triangle \mathrm{ARE}+/-}$ donors $(n=5)$.

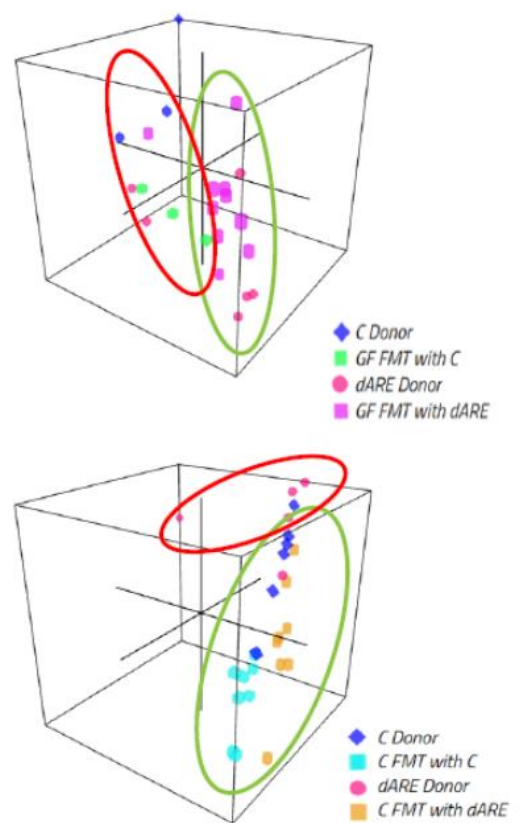

(a)

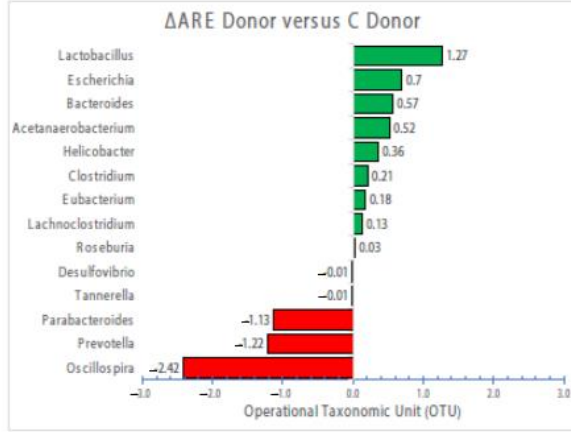

(b)

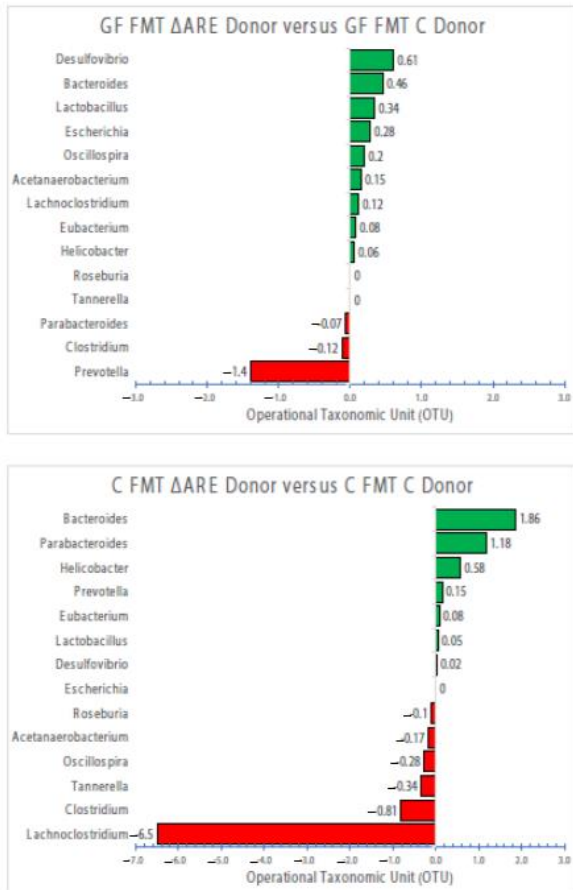

(c)

Figure 6. 3D visualization of genus communities in FMT colonies and bidirectional bar chart of the 14 genera identified in the disease transmission. Taxonomy panel at the Genus level. Panel (a) 3D representation of clustering at the genus level. Top: GF mice $(n=13) 3 \mathrm{D}$ localization is clustered closely to their respective donors $(n=9)$, similar to what is observed at the phyla level. Bottom: $\mathrm{TNF}^{\triangle \mathrm{ARE}+/-}$ donors $(n=5)$ cluster separately from $\mathrm{C}$ donors $(n=6)$ and $\mathrm{C}$ mice FMT with either donor $(n=11)$, similar to the observations at the phyla level. Panel (b) Bidirectional bar chart. BLAST TaxID (OTU) representation of the genera proportion in the donor mice $(n=9)$. Panel (c) Top: BLAST TaxID (OTU) representation of the genera proportion in GF mice $(n=13)$. Bottom: BLAST TaxID (OTU) representation of the genera proportion in Control mice $(n=16)$. These 14 genera were identified as the major key players, exhibiting significant changes in quantity between groups.

\subsection{Taxonomy: Genus Level}

After observation of the dysbiosis in $\mathrm{TNF}^{\triangle \mathrm{ARE}+/-}$ donors and GF FMT mice transplanted with sick donors, we looked deeper into the emergent Phyla, performing BLAST TaxID analysis and reanalyzing the data at the genus level, where we identified 14 key players exhibiting increased prevalence in sick donors and GF mice FMT with sick TNF ${ }^{\Delta \mathrm{ARE}+/-}$ donors, compared to their respective controls (Figure 6, panel (b) and (c)). Interestingly, we found the same emergent key players already identified in our previous publication linked with TNF mechanisms and functions [1], that have also been identified by others in an inflammatory context [10]: Lactobacillus, Escherichia, Bacteroides and Parabacteroides, Actetanaerobacterium, Helicobacter, Clostridium and Lachnoclostridium, Eubacterium, Roseburia, 
Prevotella and Oscillospira are the microorganisms with the major amplitude changes observed in BLAST TaxID (Figure 6, panel (c)). Prevotella, Lactobacillus, Clostridium and Lachnoclostridium, Bacteroides and Parabacteroides were consistently identified as having major amplitude differences between groups, indicating that they may participate in crosstalk and may be involved in a complex mechanism, working together to induce an inflammatory environment through yet to be identified mediators.

\section{Discussion}

Our main observation in this study is the transmission of an inflammatory phenotype in germ-free mice transplanted with fecal matter from genetically engineered murine donors exhibiting RA and IBD, particularly in the gut. The dysbiosis observed in murine donors showing inflammation was transmitted to germ-free mice, but not to conventional healthy mice that had a healthy microbiome, whether they were FMT with healthy C or sick

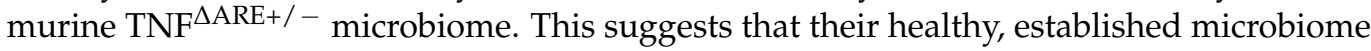
might resist colonization by an unhealthy microbiome exhibiting dysbiosis. One interesting observation is the identification of specific bacterial genera that seem to play a role in the inflammatory process driven by TNF: Lactobacillus, Escherichia, Bacteroides and Parabacteroides, Actetanaerobacterium, Helicobacter, Clostridium and Lachnoclostridium, Eubacterium, Roseburia, Prevotella and Oscillospir. Previous literature has shown that Prevotella might play a key role in RA, particularly Prevotella copri [10,33]. Roseburia has also been reported as an inflammatory signature in RA pathology [34]. Prevotella copri might be part of a causative pathobiont in RA [35,36]. Bacteroides, Eubacteria, Acetanaerobacterium, and Lactobacillus have also been shown to be RA footprints [37-39]. In addition, specific bacterial genera have been previously linked to inflammatory bowel diseases. Using 16s rRNA sequencing on pediatric patients with IBD, Hall et al. and Sila et al. observed increased prevalence of Escherichia and Prevotella, as well as decreased prevalence of Bacteroides, Clostridium, and Roseburia in the gut [40-43]. Wang et al. analyzed fecal and biopsy samples from IBD patients and found an increased prevalence of Lactobacillus [44]. There are now major indications of multiple bacteria acting together concomitantly in auto-immune disease etiology, dismissing the previously held idea that one bacteria or virus functions as the sole origin of auto-immune and inflammatory diseases [45]. However, the pathogenic mechanisms showing how gut microbiota dysbiosis in GF mice alters gut immune function and arthritis and IBD phenotypes remains to be elucidated. We collected a large amount of data, cells from the lamina propria of our mice gut and conducted flow cytometry and landscape modulating We found a strong landscape modulation of the innate lymphoid cell landscapes (ILC-1, ILC-2 and ILC-3 in line with the modifications observed in this taxonomic study, with some gender differences. Those data will be further analyzed and presented in a future immunologic publication.

For many auto-immune diseases, including RA and IBD, the specific causality has yet to be identified. In this particular study, the link joint-gut axis is interesting. Is the fact that both organs (joints and gut) are showing disease features, linked to the dysbiosis we observe? Could it be a direct effect, or an effect mediated by microbiota metabolites or other mediators? Some groups have discussed the link between the two pathologies $[8,46]$ Brakenhoff et al. concluded that activated intestinal lymphocytes in IBD patients adhere to inflamed synovial vessels using multiple adhesion molecules and their counter receptors, of which VAP-1 supports the binding of all leucocytes. These finding provide an explanation for the pathogenesis of joint inflammation in IBD patients. Kontny et al. show that IBD-related SpA may originate from the relocation of the immune response primary induced in the gut associated lymphoid tissue, to the joints [47]. Thus far, we have used TNF-antagonists and other immunosuppressants to mitigate inflammation in auto-immune diseases such as RA and IBD. Those treatments are commonly used to treat both diseases, highlining the fact that they are mechanistically related. However, these treatments have shown variable responses in patients [48]. The complex mechanisms of the gut microbiome may account for this variability. The key player genera identified 
through our research could potentially act as autoimmune disease microbial biomarkers, leading to the development of diagnostic assays that will facilitate more personalized, and hopefully more effective, patient treatment plans. Additionally, fecal transplants are now being considered to treat select chronic and inflammatory diseases and IND submissions to the FDA are increasing [49]. In this context, it becomes important to understand and identify potential risks linked to fecal transplants in humans [50,51]. Our study shows that a healthy microbiome can dominate and normalize an unhealthy fecal transplant, limiting potential risks. Our findings may help with the regulation of FMT proposed therapies in humans, by the development of a potential treatment decisional tree. One major question remains: is gut microbiota dysbiosis a cause or a consequence of gut diseases such as IBD, associated with RA? Gut microbiome and IBD and RA literature review revealed that while there has been previous research on gut microbes associated with IBD and RA, there has been no conclusive evidence showing whether gut dysbiosis is the cause, or consequence, or even both, of autoimmune diseases. In a review published by Horta-Baas $\mathrm{G}$ et al., a whole section discusses microbiome and rheumatoid arthritis, with multiple studies showing a link between the gut microbiome dysbiosis and the pathogenesis of RA, and while causation is unclear, dysbiosis is a promoter for RA progression and contributor to arthritis maintenance [52]. Maeda et al. have shown that dysbiosis contributes to arthritis development via activation of autoreactive T Cells in the Intestine [53]. This study looked at whether arthritis-prone SKG mice would develop arthritis if inoculated with fecal samples from RA patients and found that the microbiome dysbiosis is a contributor to development of arthritis in genetically prone mice. The review by Ni J et al. asking the fundamental question of the causation or correlation, concluded that, while dysbiosis is linked to IBD in humans, it is unclear if dysbiosis is a cause or a consequence of IBD [54]. Finally, Wu et al. found that the microbiome dysbiosis was linked with RA, and dysbiosis promoted and/or exacerbated RA pathogenesis and inflammation [55].

We acknowledge that our study has some limitations: This is an observational study and the correlation between identified bacteria and TNF mechanisms involved in inflammation transmission need to be investigated and confirmed in other systems, along with the mediators involved. FMTs are designed to improve microbial dysbiosis and gut microbiome diversity in patients as a therapeutic approach, not to transmit a disease. We, however, wanted to approach not the treatment side, but the transmission side, exploring the role of microbiome in auto-immune diseases onset. Moreover, the use of heterozygous and not homozygous $\mathrm{TNF}^{\mathrm{ARE}-1-}$ mice limited our results: the phenotype might have been stronger and more consistent over time with the use of homozygous donors. The features observed in degenerative cartilage disease might also account for the age of the colony: our mice survived until 6 to 9 months of age, when some arthritis degradation can naturally be observed. We also worked with relatively small colony numbers, because we encountered numerous challenges and deaths, since the mice were very fragile and difficult to maintain in an isolated environment.

\section{Conclusions}

Overall, our results confirm the involvement of the gut microbiome in the joint-gut axis and the potential role played by TNF in the inflammatory process and in disease etiology, driven by several specific microbes. Our results further open the door to a new field of research: investigating the interplay between the gut microbiome, the inflammatory process and disease etiology mediated via inflammatory mechanisms. Our future studies will involve the elucidation of mechanistic correlates between the microbiome key players identified in inflammation and autoimmune disease.

Supplementary Materials: The following are available online at https://www.mdpi.com/article/10 .3390/microorganisms10010073/s1, Figure S1: title Study design.

Author Contributions: Conceptualization, K.A.C. and O.G.; Data curation, V.E., D.L.S., L.T., S.P., J.-N.P., L.S.-Q. and O.G.; Formal analysis, V.E., D.L.S., W.W.W., L.S.-Q. and O.G.; Investigation, V.E. 
and O.G.; Methodology, O.G. and F.M.; Project administration, L.T.; Resources, W.W.W., J.-N.P., L.S.-Q. and F.M.; Software, V.E., D.L.S., S.P., L.S.-Q. and O.G.; Supervision, K.A.C. and O.G.; Validation, W.W.W.; Visualization, V.E. and D.L.S.; Writing—original draft, O.G.; Writing—review \& editing, V.E. and K.A.C. All authors have read and agreed to the published version of the manuscript.

Funding: This research received no external funding.

Institutional Review Board Statement: All animal procedures and the Animal Study Proposal (ASP) were reviewed and approved by the U.S. Food and Drug Administration (FDA) Institutional Animal Care and Use Committee (IACUC).

Data Availability Statement: All metadata have been deposited to NCBI microbiome database registry depository, in the Sequences Read Archives (SRA): https:/ / www.ncbi.nlm.nih.gov/sra/ (accessed on 15 December 2021). Flow cytometry, Luminex raw data are available on demand.

Acknowledgments: The authors want to thank John Dennis and the animal facility care takers for their valuable help, hard work, and expertise. We also want to thank Fabio Cominelli, Case Western Reserve University, Cleveland, $\mathrm{OH}$, USA, for providing the $\mathrm{TNF}^{\triangle \mathrm{ARE}}$ mice, as well as Carole Sourbier for her assistance in statistical analysis and reading of the manuscript; We thank Tao Wang, Tao Xi, and Desiree Denman, Histoserv and American Histolab, Germantown, MD, USA, for helping with histology and figures and Marianna Faradzheva for assistance with the 3D cluster figures. Finally, we would also like to thank our Summer students Lismari Reyes-Munoz and Mokhinur Shokhalillulo for their help with the experiments.

Conflicts of Interest: The authors are government employees and declare no conflict of interest.

Disclaimer: This manuscript reflects the views of the authors and should not be construed to represent FDA's views or policies.

\section{References}

1. Gabay, O.; Vicenty, J.; Zack-Taylor, A.; Tiffany, L.; Wunderlin, G.; Smith, D.; Reyes-Munoz, L.; Edwards, V.; Wu, W.W.; Phue, J.N.; et al. Exposure to TNF antagonist therapies induces variations of the gut microbiota in an in vivo model using healthy mice. Jt. Bone Spine 2020, 87, 175-178. [CrossRef]

2. Zheng, D.; Liwinski, T.; Elinav, E. Interaction between microbiota and immunity in health and disease. Cell Res. 2020, 30, 492-506. [CrossRef]

3. Zhang, X.; Chen, B.D.; Zhao, L.D.; Li, H. The Gut Microbiota: Emerging Evidence in Autoimmune Diseases. Trends Mol. Med. 2020, 26, 862-873. [CrossRef]

4. Rinninella, E.; Raoul, P.; Cintoni, M.; Franceschi, F.; Miggiano, G.A.D.; Gasbarrini, A.; Mele, M.C. What is the Healthy Gut Microbiota Composition? A Changing Ecosystem across Age, Environment, Diet, and Diseases. Microorganisms 2019, 7, 14. [CrossRef]

5. $\quad$ Arumugam, M.; Raes, J.; Pelletier, E.; Le Paslier, D.; Yamada, T.; Mende, D.R.; Fernandes, G.R.; Tap, J.; Bruls, T.; Batto, J.M.; et al. Enterotypes of the human gut microbiome. Nature 2011, 473, 174-180. [CrossRef]

6. Scher, J.U.; Littman, D.R.; Abramson, S.B. Microbiome in Inflammatory Arthritis and Human Rheumatic Diseases. Arthritis Rheumatol. 2016, 68, 35-45. [CrossRef] [PubMed]

7. Morais, L.H.; Schreiber, H.L.T.; Mazmanian, S.K. The gut microbiota-brain axis in behaviour and brain disorders. Nat. Rev. Microbiol. 2021, 19, 241-255. [CrossRef]

8. Zaiss, M.M.; Joyce Wu, H.J.; Mauro, D.; Schett, G.; Ciccia, F. The gut-joint axis in rheumatoid arthritis. Nat. Rev. Rheumatol. 2021, 17, 224-237. [CrossRef] [PubMed]

9. Bach, J.F. The effect of infections on susceptibility to autoimmune and allergic diseases. N. Engl. J. Med. 2002, 347, 911-920. [CrossRef] [PubMed]

10. Scher, J.U.; Sczesnak, A.; Longman, R.S.; Segata, N.; Ubeda, C.; Bielski, C.; Rostron, T.; Cerundolo, V.; Pamer, E.G.; Abramson, S.B.; et al. Expansion of intestinal Prevotella copri correlates with enhanced susceptibility to arthritis. Elife 2013, 2, e01202. [CrossRef] [PubMed]

11. Kang, D.W.; Adams, J.B.; Coleman, D.M.; Pollard, E.L.; Maldonado, J.; McDonough-Means, S.; Caporaso, J.G.; Krajmalnik-Brown, R. Long-term benefit of Microbiota Transfer Therapy on autism symptoms and gut microbiota. Sci. Rep. 2019, 9, 5821. [CrossRef] [PubMed]

12. Sun, J.; Xu, J.; Ling, Y.; Wang, F.; Gong, T.; Yang, C.; Ye, S.; Ye, K.; Wei, D.; Song, Z.; et al. Fecal microbiota transplantation alleviated Alzheimer's disease-like pathogenesis in APP/PS1 transgenic mice. Transl. Psychiatry 2019, 9, 189. [CrossRef]

13. Xue, L.J.; Yang, X.Z.; Tong, Q.; Shen, P.; Ma, S.J.; Wu, S.N.; Zheng, J.L.; Wang, H.G. Fecal microbiota transplantation therapy for Parkinson's disease: A preliminary study. Medicine 2020, 99, e22035. [CrossRef] [PubMed] 
14. Basson, A.R.; Zhou, Y.; Seo, B.; Rodriguez-Palacios, A.; Cominelli, F. Autologous fecal microbiota transplantation for the treatment of inflammatory bowel disease. Transl. Res. 2020, 226, 1-11. [CrossRef] [PubMed]

15. Sampson, T.R.; Debelius, J.W.; Thron, T.; Janssen, S.; Shastri, G.G.; Ilhan, Z.E.; Challis, C.; Schretter, C.E.; Rocha, S.; Gradinaru, V.; et al. Gut Microbiota Regulate Motor Deficits and Neuroinflammation in a Model of Parkinson's Disease. Cell 2016, 167, 1469-1480.e12. [CrossRef]

16. Barichella, M.; Severgnini, M.; Cilia, R.; Cassani, E.; Bolliri, C.; Caronni, S.; Ferri, V.; Cancello, R.; Ceccarani, C.; Faierman, S.; et al Unraveling gut microbiota in Parkinson's disease and atypical parkinsonism. Mov. Disord. 2019, 34, 396-405. [CrossRef]

17. Ridaura, V.K.; Faith, J.J.; Rey, F.E.; Cheng, J.; Duncan, A.E.; Kau, A.L.; Griffin, N.W.; Lombard, V.; Henrissat, B.; Bain, J.R.; et al Gut microbiota from twins discordant for obesity modulate metabolism in mice. Science 2013, 341, 1241214. [CrossRef]

18. Huybers, S.; Apostolaki, M.; van der Eerden, B.C.; Kollias, G.; Naber, T.H.; Bindels, R.J.; Hoenderop, J.G. Murine TNF(DeltaARE) Crohn's disease model displays diminished expression of intestinal $\mathrm{Ca}^{2+}$ transporters. Inflamm. Bowel Dis. $2008,14,803-811$. [CrossRef] [PubMed]

19. Banerjee, A.; Herring, C.A.; Chen, B.; Kim, H.; Simmons, A.J.; Southard-Smith, A.N.; Allaman, M.M.; White, J.R.; Macedonia, M.C.; McKinley, E.T.; et al. Succinate Produced by Intestinal Microbes Promotes Specification of Tuft Cells to Suppress Ileal Inflammation. Gastroenterology 2020, 159, 2101-2115.e5. [CrossRef] [PubMed]

20. Sanctuary, M.R.; Huang, R.H.; Jones, A.A.; Luck, M.E.; Aherne, C.M.; Jedlicka, P.; de Zoeten, E.F.; Collins, C.B. miR-106a deficiency attenuates inflammation in murine IBD models. Mucosal Immunol. 2019, 12, 200-211. [CrossRef]

21. Kontoyiannis, D.; Pasparakis, M.; Pizarro, T.T.; Cominelli, F.; Kollias, G. Impaired on/off regulation of TNF biosynthesis in mice lacking TNF AU-rich elements: Implications for joint and gut-associated immunopathologies. Immunity 1999, 10, 387-398. [CrossRef]

22. Cominelli, F.; Arseneau, K.O.; Rodriguez-Palacios, A.; Pizarro, T.T. Uncovering Pathogenic Mechanisms of Inflammatory Bowel Disease Using Mouse Models of Crohn's Disease-Like Ileitis: What is the Right Model? Cell Mol. Gastroenterol. Hepatol. 2017, 4, 19-32. [CrossRef]

23. Bamias, G.; Arseneau, K.O.; Cominelli, F. Mouse models of inflammatory bowel disease for investigating mucosal immunity in the intestine. Curr. Opin. Gastroenterol. 2017, 33, 411-416. [CrossRef]

24. Pizarro, T.T.; Arseneau, K.O.; Bamias, G.; Cominelli, F. Mouse models for the study of Crohn's disease. Trends Mol. Med. 2003, 9 , 218-222. [CrossRef]

25. Armaka, M.; Apostolaki, M.; Jacques, P.; Kontoyiannis, D.L.; Elewaut, D.; Kollias, G. Mesenchymal cell targeting by TNF as a common pathogenic principle in chronic inflammatory joint and intestinal diseases. J. Exp. Med. 2008, 205, 331-337. [CrossRef]

26. Gabay, O.; Vicenty, J.; Smith, D.; Tiffany, L.; Ascher, J.; Curry, T.; Dennis, J.; Clouse, K.A. Using a Model of Germ-Free Animals to Study the Impact of Gut Microbiome in Research: A Step by Step Sterility Setting and Management. Methods Protoc. 2020, 3 , 18 [CrossRef] [PubMed]

27. Simonyan, V.; Mazumder, R. High-Performance Integrated Virtual Environment (HIVE) Tools and Applications for Big Data Analysis. Genes 2014, 5, 957-981. [CrossRef] [PubMed]

28. Shamsaddini, A.; Pan, Y.; Johnson, W.E.; Krampis, K.; Shcheglovitova, M.; Simonyan, V.; Zanne, A.; Mazumder, R. Census-based rapid and accurate metagenome taxonomic profiling. BMC Genom. 2014, 15, 918. [CrossRef] [PubMed]

29. Liu, X.; Zou, Q.; Zeng, B.; Fang, Y.; Wei, H. Analysis of fecal Lactobacillus community structure in patients with early rheumatoid arthritis. Curr. Microbiol. 2013, 67, 170-176. [CrossRef] [PubMed]

30. Catrina, A.I.; Deane, K.D.; Scher, J.U. Gene, environment, microbiome and mucosal immune tolerance in rheumatoid arthritis. Rheumatology 2016, 55, 391-402. [CrossRef] [PubMed]

31. Doherty, M.K.; Ding, T.; Koumpouras, C.; Telesco, S.E.; Monast, C.; Das, A.; Brodmerkel, C.; Schloss, P.D. Fecal Microbiota Signatures Are Associated with Response to Ustekinumab Therapy among Crohn's Disease Patients. mBio 2018, 9, e02120-17. [CrossRef] [PubMed]

32. Matsuoka, K.; Kanai, T. The gut microbiota and inflammatory bowel disease. Semin. Immunopathol. 2015, 37, 47-55. [CrossRef]

33. Fehlner-Peach, H.; Magnabosco, C.; Raghavan, V.; Scher, J.U.; Tett, A.; Cox, L.M.; Gottsegen, C.; Watters, A.; Wiltshire-Gordon, J.D.; Segata, N.; et al. Distinct Polysaccharide Utilization Profiles of Human Intestinal Prevotella copri Isolates. Cell Host Microbe 2019, 26, 680-690.e5. [CrossRef] [PubMed]

34. Wei, J.; Zhang, C.; Zhang, Y.; Zhang, W.; Doherty, M.; Yang, T.; Zhai, G.; Obotiba, A.D.; Lyu, H.; Zeng, C.; et al. Association between gut microbiota and symptomatic hand osteoarthritis: Data from the Xiangya Osteoarthritis Study. Arthritis Rheumatol. 2021, 73, 1656-1662. [CrossRef]

35. Larsen, J.M. The immune response to Prevotella bacteria in chronic inflammatory disease. Immunology 2017, 151, 363-374. [CrossRef] [PubMed]

36. Kim, D.; Kim, W.U. Editorial: Can Prevotella copri Be a Causative Pathobiont in Rheumatoid Arthritis? Arthritis Rheumatol. 2016, 68, 2565-2567. [CrossRef] [PubMed]

37. Muniz Pedrogo, D.A.; Chen, J.; Hillmann, B.; Jeraldo, P.; Al-Ghalith, G.; Taneja, V.; Davis, J.M.; Knights, D.; Nelson, H.; Faubion, W.A.; et al. An Increased Abundance of Clostridiaceae Characterizes Arthritis in Inflammatory Bowel Disease and Rheumatoid Arthritis: A Cross-sectional Study. Inflamm. Bowel Dis. 2019, 25, 902-913. [CrossRef] 
38. Chen, J.; Toyomasu, Y.; Hayashi, Y.; Linden, D.R.; Szurszewski, J.H.; Nelson, H.; Farrugia, G.; Kashyap, P.C.; Chia, N.; Ordog, T. Altered gut microbiota in female mice with persistent low body weights following removal of post-weaning chronic dietary restriction. Genome Med. 2016, 8, 103. [CrossRef]

39. Chen, J.; Wright, K.; Davis, J.M.; Jeraldo, P.; Marietta, E.V.; Murray, J.; Nelson, H.; Matteson, E.L.; Taneja, V. An expansion of rare lineage intestinal microbes characterizes rheumatoid arthritis. Genome Med. 2016, 8, 43. [CrossRef]

40. Hall, L.J.; Walshaw, J.; Watson, A.J. Gut microbiome in new-onset Crohn's disease. Gastroenterology 2014, 147, 932-934. [CrossRef]

41. Sila, S.; Jelic, M.; Trivic, I.; Tambic Andrasevic, A.; Hojsak, I.; Kolacek, S. Altered Gut Microbiota Is Present in Newly Diagnosed Pediatric Patients With Inflammatory Bowel Disease. J. Pediatr. Gastroenterol. Nutr. 2020, 70, 497-502. [CrossRef]

42. Cardoneanu, A.; Mihai, C.; Rezus, E.; Burlui, A.; Popa, I.; Cijevschi Prelipcean, C. Gut microbiota changes in inflammatory bowel diseases and ankylosing spondilytis. J. Gastrointestin. Liver Dis. 2021, 30, 46-54. [CrossRef]

43. Lucke, K.; Miehlke, S.; Jacobs, E.; Schuppler, M. Prevalence of Bacteroides and Prevotella spp. in ulcerative colitis. J. Med. Microbiol. 2006, 55 Pt 5, 617-624. [CrossRef]

44. Wang, W.; Chen, L.; Zhou, R.; Wang, X.; Song, L.; Huang, S.; Wang, G.; Xia, B. Increased proportions of Bifidobacterium and the Lactobacillus group and loss of butyrate-producing bacteria in inflammatory bowel disease. J. Clin. Microbiol. 2014, 52, 398-406. [CrossRef]

45. Elicabe, R.J.; Cargnelutti, E.; Serer, M.I.; Stege, P.W.; Valdez, S.R.; Toscano, M.A.; Rabinovich, G.A.; Di Genaro, M.S. Lack of TNFR p55 results in heightened expression of IFN-gamma and IL-17 during the development of reactive arthritis. J. Immunol. 2010, 185, 4485-4495. [CrossRef] [PubMed]

46. Brakenhoff, L.K.; van der Heijde, D.M.; Hommes, D.W.; Huizinga, T.W.; Fidder, H.H. The joint-gut axis in inflammatory bowel diseases. J. Crohns Colitis 2010, 4, 257-268. [CrossRef] [PubMed]

47. Kontny, E.; Dmowska-Chalaba, J.; Kwiatkowska, B.; Maslinski, W. Cytokines and integrins related to inflammation of joint and gut in patients with spondyloarthritis and inflammatory bowel disease. Reumatologia 2017, 55, 276-283. [CrossRef]

48. Simsek, I. Predictors of response to TNF inhibitors in rheumatoid arthritis-Do we have new tools for personalized medicine? Bull. NYU Hosp. Jt. Dis. 2012, 70, 187-190. [PubMed]

49. Marietta, E.; Mangalam, A.K.; Taneja, V.; Murray, J.A. Intestinal Dysbiosis in, and Enteral Bacterial Therapies for, Systemic Autoimmune Diseases. Front. Immunol. 2020, 11, 573079. [CrossRef]

50. Pamer, E.G. Fecal microbiota transplantation: Effectiveness, complexities, and lingering concerns. Mucosal Immunol. 2014, 7, 210-214. [CrossRef]

51. Blaser, M.J. Fecal Microbiota Transplantation for Dysbiosis_Predictable Risks. N. Engl. J. Med. 2019, 381, 2064-2066. [CrossRef]

52. Horta-Baas, G.; Romero-Figueroa, M.D.S.; Montiel-Jarquin, A.J.; Pizano-Zarate, M.L.; Garcia-Mena, J.; Ramirez-Duran, N. Intestinal Dysbiosis and Rheumatoid Arthritis: A Link between Gut Microbiota and the Pathogenesis of Rheumatoid Arthritis. J. Immunol. Res. 2017, 2017, 4835189. [CrossRef] [PubMed]

53. Maeda, Y.; Kurakawa, T.; Umemoto, E.; Motooka, D.; Ito, Y.; Gotoh, K.; Hirota, K.; Matsushita, M.; Furuta, Y.; Narazaki, M.; et al Dysbiosis Contributes to Arthritis Development via Activation of Autoreactive T Cells in the Intestine. Arthritis Rheumatol. 2016, 68, 2646-2661. [CrossRef] [PubMed]

54. Ni, J.; Wu, G.D.; Albenberg, L.; Tomov, V.T. Gut microbiota and IBD: Causation or correlation? Nat. Rev. Gastroenterol. Hepatol. 2017, 14, 573-584. [CrossRef] [PubMed]

55. Wu, W.H.; Zegarra-Ruiz, D.F.; Diehl, G.E. Intestinal Microbes in Autoimmune and Inflammatory Disease. Front. Immunol. 2020, 11, 597966. [CrossRef] 